\title{
APPLICATION OF SPECTRAL INDUCED POLARIZATION AND ELECTRICAL IMPEDANCE TOMOGRAPHY ON MIXTURES OF BIOCHARS AND ACTIVE CARBONS WITH SAND
}

\author{
Franz-Hubert Haegel, Forschungszentrum Jülich, Germany \\ Egon Zimmermann, Forschungszentrum Jülich, Germany \\ Nicolai D. Jablonowski, Forschungszentrum Jülich, Germany \\ Odilia Esser, Forschungszentrum Jülich, Germany \\ Johan A. Huisman, Forschungszentrum Jülich, Germany \\ Harry Vereecken, Forschungszentrum Jülich, Germany
}

\begin{abstract}
Biochar is currently of emerging interest, because it is a by-product of the increasing energetic use of organic waste and energy crops via pyrolysis. It is discussed as a modifier for soil to improve fertility and store carbon for long-term. The benefit of carbon for fertility is well known from terra preta (anthropogenic "black soil") in Amazonia since centuries, but many questions are still open, e.g. concerning the influence of charcoal on the hydrology in different soils. The large variety of feed material and pyrolysis techniques may result in different effects concerning the properties of soil. Spectral induced polarization (SIP) was considered as a method which can contribute to answer some of the questions. Therefore, a series of studies was performed on mixtures of 4 different biochars and commercial active carbon with sand. The results obtained provide additional information on the characterization of different types of charcoal and on the fertilizing effect of biochar. Considerable differences were found for biochars depending on the pyrolysis technique for both the real and the imaginary part of complex conductivity. The time dependence of the release of ions from the carbonaceous material could also be monitored. Based on the results of SIP, a 2D experiment was performed with electrical impedance tomography (EIT) which proved the suitability of the method to locate biochar and active carbon in sand. Since EIT can be applied at different scales, it has high potential for studying the influence of biochar on the hydraulic properties of soil and on its fertilizing effect in the laboratory and in the field.
\end{abstract}

\section{Introduction}

Spectral induced polarization (SIP) is currently investigated as an emerging technique in soil science in the laboratory (Cassiani et al., 2009; Revil and Skold, 2011) as well as in the field (Hördt et al., 2007; Williams et al., 2009). It has successfully been applied for determining hydraulic properties (Börner et al., 1996; Weller and Börner, 1996; Slater, 2007; Hördt et al., 2009; Weller et al., 2010; Breede et al. ; 2011, Koch et al., 2011), for characterizing materials and their interfacial chemistry (Leroy et al., 2009; Schmutz et al. 2010; Vaudelet et al., 2011'a; Vaudelet et al., 2011 ; Skold et al. 2011), for examining biological processes (Slater et al., 2007) and determining the extent of plumes (Flores Orozco et al., 2011) at contaminated sites.

This potential of SIP for successfully studying hydraulic and interfacial properties of unconsolidated porous media at different scales was considered to be helpful for investigating the influence of biochar on soil. This subject has become a topic since increasing quantities of biochar are available as a by-product from the use of biomaterials for fuel production (Lehmann, 2007; Sohi et al., 2011). Many papers have been published within the last 3 years considering different aspects of biochar generation and its application in soil including the potential effect for climate protection due to long- 
term carbon storage (Jha et al., 2010). The use of carbonaceous material as a soil modifier is well known for terra preta in South America. This type of anthropogenic soil is the result of cultivation with charcoal by Indians of South America for centuries. Since tropical soil is usually poor in nutrients, the ions contained in the charcoal are important for improving soil quality. Improved crop yield was also found in many other types of soils, but the fertilizing effect may not be as important for soils in temperate climate. Many other effects of the addition of biochar to soil have been studied in different soil systems, like the influence of biochar on gas exchange (Jha et al., 2010) and microbial activity (Lehmann et al. 2011). However, there are few papers concerning the change of hydraulic properties of soil with biochar (Dumroese et al., 2011; Uzoma et al., 2011; Laird et al., 2010; Brockhoff et al., 2010) and the effects are not consistent for all studies. This result is not really astonishing, because there is a large variety of soils and biochars. Many different feed materials have been used to make biochar. Waste material from e.g. food production as well as wood and other plant materials are frequent sources. The organic materials are thermally treated under deficiency or exclusion of oxygen, i.e. pyrolized, at elevated temperature $\left(>400{ }^{\circ} \mathrm{C}\right)$. The conditions for the process (in particular temperature and contact time) can be varied within wide margins. Gaseous and liquid components obtained from the feed material are used as fuels or raw materials for chemicals. The remaining biochar must be disposed or preferably be used for another purpose, e.g. for long-term storage of carbon and for the amendment of soil. Depending on the temperature and the contact time, the process of carbonification of the organic material is more or less complete and thus the composition varies for different pyrolysis techniques. Materials which were treated at relatively low temperature for short time usually contain considerable amounts of organic compounds which can be desorbed by water from the biochar (Kookana et al., 2011), whereas materials pyrolized at high temperature or for longer time become more like graphite (Brewer et al., 2009). The polymers forming the matrix of the organic feed materials are insulators. Pure graphite, however, exhibits high electron conductivity. Thus, the electrical properties of biochar, which forms an intermediate state, are expected to be dependent on the process parameters of pyrolysis.

There are some papers on spectral induced polarization of materials containing graphite (Wong, 1979; Vanhala and Peltoniemi, 1992) in the geophysical literature. Much more impedance data on systems containing different kinds of carbon are available from another field of current research, namely the development and investigation of double layer capacitors (Sharma and Bhatti, 2010). Since graphite is an electronic conductor, charge transfer across the interface may be involved (Wong, 1979; Wong and Strangway, 1981; Vanhala and Peltoniemi, 1992). In addition to impedance spectroscopy, cyclic voltammetry is frequently used for determining the electrical properties of double layer capacitors including redox reactions at the interface between carbon and other components.

The aim of this work was to investigate mixtures of sand and biochar with spectral induced polarization (SIP) in the frequency range between $1 \mathrm{mHz}$ to $45 \mathrm{kHz}$ in order to evaluate whether they exhibit a spectral response which can be used for characterizing the material. In a second step, the signal of complex conductivity determined with SIP should be used for locating the charcoal in a sand matrix with electrical impedance tomography (EIT).

\section{Materials and Methods}

\section{Materials and Basic Characterization}

Sand F36 with $97 \%$ of the material having a grain size between $125-250 \mu \mathrm{m}$ was obtained from Quarzwerke Hürth. Active carbon 100-400 mesh (particle size 37-149 $\mu \mathrm{m}$ ) was purchased from SigmaAldrich. The commercially available biochar 1 was prepared under exclusion of oxygen from hardwood at $450-500^{\circ} \mathrm{C}$ (Dynamotive, USA) and used as received. Biochar 2 was a commercial barbecue charcoal from deciduous wood (beech and oak) pyrolized at $500{ }^{\circ} \mathrm{C}$ for $13-18 \mathrm{~h}$. Some of the material was crushed to a coarse powder and a fraction with particle size between 1 and $2 \mathrm{~mm}$ was separated by 
sieving. Another part was milled in a planetary mill (Retsch, PM 400) at $200 \mathrm{rpm}$ to a fine powder. Biochar 3 was produced using flash pyrolysis at $500{ }^{\circ} \mathrm{C}$ with $1 \mathrm{~s}$ contact time from spruce wood. Biochar 4 was made by gasification of deciduous wood (beech and oak) at $1100{ }^{\circ} \mathrm{C}$ for $30 \mathrm{~s}$. All biochars except the sieve fraction of biochar 2 were fine powders. The electrolyte used to prepare the saturated sand-charcoal mixtures was $4 \mathrm{mM} \mathrm{NaCl}$.

Conductivity and $\mathrm{pH}$ were determined with a $\mathrm{pH} /$ Cond 340i from WTW (Weilheim, Germany).

\section{Spectral Induced Polarization}

SIP measurements were made using the equipment and design considerations presented in Zimmermann et al. $\left(2008^{\mathrm{a}}\right)$. They were performed in an air-conditioned room at $20.5 \pm 1{ }^{\circ} \mathrm{C}$. The results are obtained as complex electrical conductivity $\sigma^{*}$ and can be expressed as the sum of a real part $\sigma^{\prime}$ and an imaginary part $\sigma^{\prime \prime}$ describing the uniform transport and the change of the equilibrium distribution of ions in the external electrical field (Equation 1).

$$
\sigma^{*}=\sigma^{\prime}+\mathrm{i} \sigma^{\prime \prime}
$$

Two different sample holders were used for SIP measurements: a rectangular box with the top open to air and a closed cylindrical column. The box was $60.5 \mathrm{~cm}$ long, $5.725 \mathrm{~cm}$ wide and $8 \mathrm{~cm}$ high. The distance of the current electrodes was $35.7 \mathrm{~cm}$ and the potential electrodes were placed symmetrically between them with a separation distance of $10.6 \mathrm{~cm}$. Pieces of commercial bath sponges of $4 \mathrm{~cm}$ thickness were placed between the current electrodes and the sand-charcoal mixture in order to save the electrodes from soiling and to reduce the required amount of material. The equipment was tested with $4 \mathrm{mM} \mathrm{NaCl}$. No influence of the sponges on the SIP measurements was observed. The cylindrical column had a height of $30 \mathrm{~cm}$ and an inner diameter of $6 \mathrm{~cm}$. Porous bronze plates were used as current electrodes at the top and the bottom. The potential electrodes were placed with equal distances between the current electrodes. $\mathrm{Ag} / \mathrm{AgCl}$ electrodes filled with $4 \mathrm{mM} \mathrm{NaCl}$ were used for potential measurement.

$2 \%$ (w/w with respect to the mass of sand) of charcoal was added to air-dry sand and the materials were mixed by stirring with a spatula. The mixture was wetted with electrolyte solution and stirred again. The materials were filled into the sample holders in portions. Therefore some electrolyte was first poured into the sample holders and then the solid materials were added so that a slight excess of liquid remained. This mixture was stirred with a spatula in order to remove air and ensure complete saturation. The rectangular sample holder was not completely filled. The space outside the bronze electrodes was only filled with electrolyte and the filling height of the solid material was about $2.5 \mathrm{~cm}$. The exact height was measured with a caliper rule. Since the surface of the solid mixture was not exactly flat in the rectangular sample holder, the accuracy of the cell constant for calculating the conductivity had an error of about $10 \%$.

\section{Electrical Impedance Tomography}

Electrical impedance tomography was performed in a cylindrical container made from PVC with a height of $6.2 \mathrm{~cm}$ and an inner diameter of $19 \mathrm{~cm}$. The container was equipped with 16 bores each for cylindrical brass electrodes with a diameter of $6 \mathrm{~mm}$ which were used for current injection and potential measurements. The container was filled to a height of $4 \mathrm{~cm}$ with sand containing structures of two different sand-charcoal mixtures (active carbon and biochar 4), so that the upper and lower boundary were approximately symmetrical with respect to the height of the centre of the brass electrodes $(2 \mathrm{~cm}$ above the bottom). The surface was not absolutely flat, but had a roughness of about $2 \mathrm{~mm}$. 16 configurations of current injection were measured. Data were collected simultaneously for all potential electrodes with the laboratory EIT system described in detail by Zimmermann et al. $\left(2008^{\mathrm{b}}\right)$. 
A regularized iterative reconstruction routine programmed in MATLAB was used for the imaging of electrical impedance. The inverse problem was solved as an optimization problem. At each iteration, starting from a homogeneous distribution of electrical conductivity $\sigma_{0}$, an objective function consisting of the data misfit and a regularization term (here the roughness of the distribution) was minimized (deGroot-Hedlin and Constable, 1990). The data misfit is the squared difference between the measured sensor signals and the theoretical sensor signals. In order to calculate the theoretical signals, 3D modelling based on the finite element method was used, employing an irregular mesh of tetrahedrons (Kwon and Bang, 1997; Xu et al., 2005). This method was used to solve the Poisson equation (Equation 2)

$$
\nabla \cdot[\sigma *(\mathbf{r}) \nabla V(\mathbf{r})]=-I \delta(\mathbf{r})
$$

which describes the relation between the electrical potential $\mathrm{V}$ in the medium with the complex conductivity distribution $\sigma^{*}$ and a quasi static point-source current injection I. $\delta$ denotes the Dirac delta function (Zimmermann et al., 2008 ${ }^{\mathrm{b}}$ ).

\section{Results and Discussion}

SIP measurements were performed on 4 different biochars and a commercial active carbon with a defined particle size distribution for determining the influence of carbonaceous material on the electrical properties of sand. The active carbon and the biochar with the largest response were also used for testing the possibility to locate the chars using EIT in a 2D-experiment.

\section{Spectral Induced Polarization}

First spectra of the complex conductivity of sand-charcoal mixtures were measured immediately after sample preparation. They were recorded from high frequency $(45 \mathrm{kHz})$ to low frequency $(1 \mathrm{mHz})$ and directly in reverse direction with a different set of frequencies. The total time for the whole cycle was about $2.5 \mathrm{~h}$. The initial measurements of all sand-charcoal mixtures showed considerable differences between both directions of frequency change indicating that the complex conductivity of the samples was strongly time-dependent. This was not the case for the pure sand, which showed only small changes with time. Time-dependent complex conductivity was also found for subsequent measurements. Since most of the experiments were performed in the open rectangular sample holder, the samples slowly dried due to the evaporation of water. This effect was comparably slow and played no important role during the time required for a single run, but could have influenced the results for longer time lags. Time-dependent results were also obtained for SIP measurements in the closed column indicating that drying could not be the only reason for this behavior.

The measurements on the mixture of active carbon and sand showed an unexpected behavior. The real part of conductivity $\sigma$ ' was rather high, about the same as the pure electrolyte. It also showed a very strong decrease during the first measurement cycle (Figure 1a). The arrow above the curve indicates the direction in which frequency was changed during the first half-cycle. Note that the time for determining a single value of complex conductivity strongly increases with decreasing frequency. Therefore, the slope of the curve increases in the low frequency range. For the reverse half-cycle, the signal already seems to level off, but a decrease of $\sigma^{\prime}$ can also be observed for the second measurement which was started immediately after the first one (Figure 1a, olive curve). Even after some hours, a continued reduction of $\sigma^{\prime}$ was visible. However, an increase of $\sigma^{\prime}$ was observed one day after preparation. During this measurement the conductivity further increased. 
The imaginary part of conductivity $\sigma$ " was also time-dependent (Figure 1b), but to a lesser extent for the first measurement cycle. The signal continuously decreased in this case. A maximum of the imaginary part of conductivity was found at about $10 \mathrm{~Hz}$ for this commercial product which has a well defined particle size between 37 and $149 \mu \mathrm{m}$. The peak is relatively broad from about $10 \mathrm{mHz}$ to about 1 $\mathrm{kHz}$, although the particle size distribution is relatively narrow. The maximum value of $\sigma$ " in this range is more than two orders of magnitude lower than $\sigma$ '.
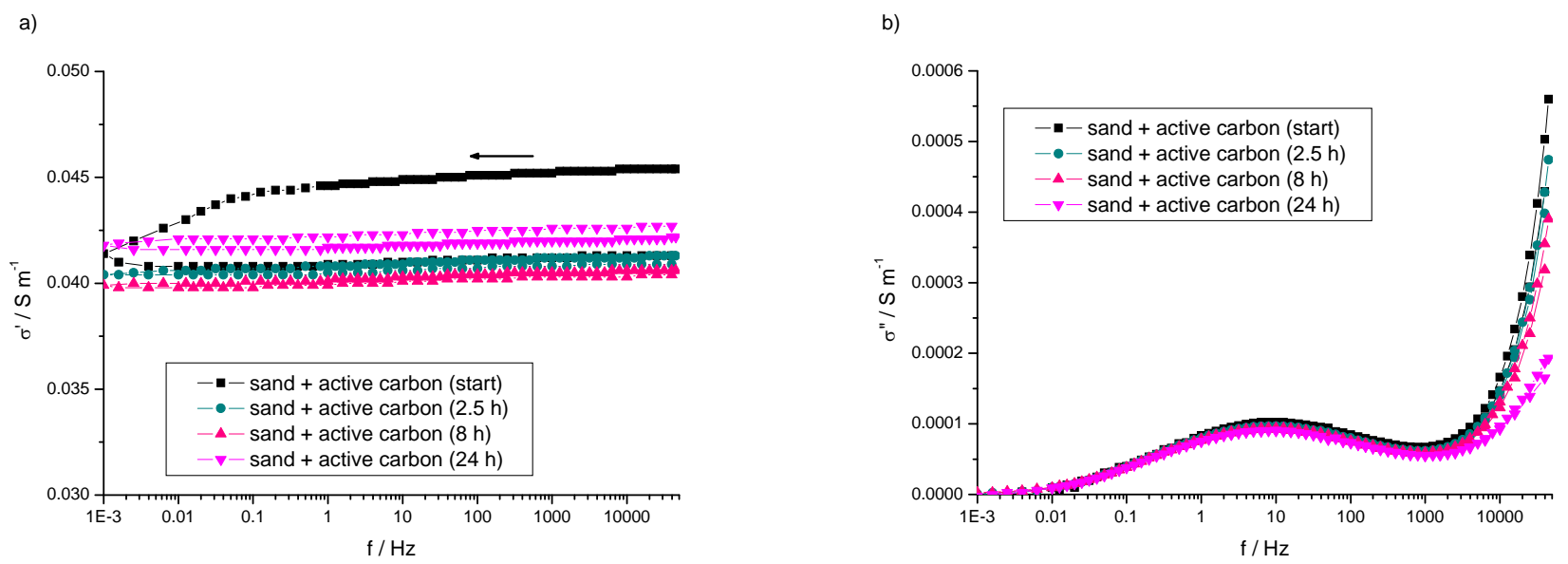

Figure 1: Time dependent plots of $\sigma^{\prime}$ (a) and $\sigma^{\prime \prime}(\mathrm{b})$ for active carbon (100-400 mesh)

The behavior of the biochars was different. They all showed an increase of $\sigma$ ' for the first and successive measurements. The curves for biochar 3 are shown in Figure 2a. The real part of conductivity was higher than that for pure sand. The values for biochars 1-3 were similar, roughly one third of the conductivity of pure electrolyte. All biochars also exhibited an increase of $\sigma$ " with time. Pure sand showed only a small increase of both $\sigma$ ' and $\sigma$ " during the first cycle. No distinct maxima were observed for biochars 1-3 and for pure sand.
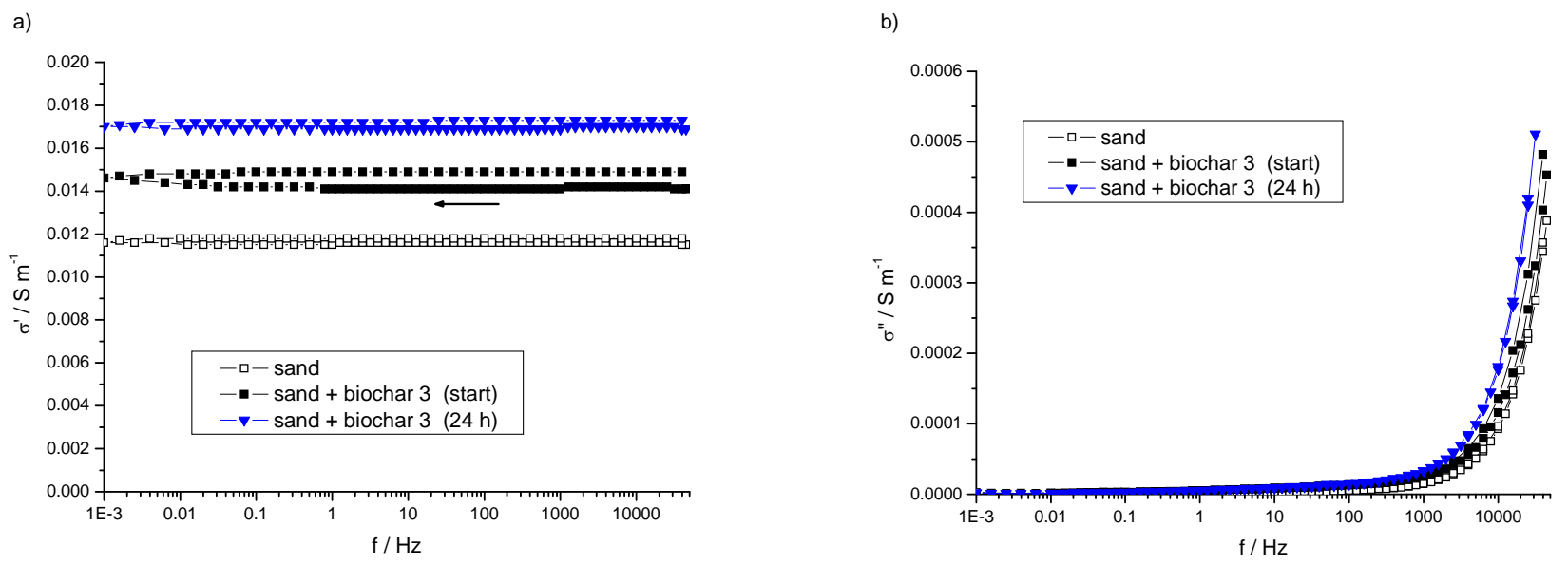

Figure 2: Time dependent plots of $\sigma^{\prime}$ (a) and $\sigma^{\prime \prime}(\mathrm{b})$ for biochar 3 
The spectra for biochar 4 looked much different. The values of $\sigma$ ' were much higher. They showed an increase at higher frequencies (Figure 3a), so that a decrease of the real part of conductivity was found during the first half-cycle starting from high frequency. This decrease, however, is not comparable to that found for active carbon. The shape of the curve was similar for all successive measurements. The time-dependent increase of $\sigma$ ' was much higher than for the other biochars. The imaginary part of conductivity and its increase were also considerably higher for biochar 4 as compared to biochars 1-3 (Figure 3b). The form of the curve suggests a slight maximum between 10 and $100 \mathrm{~Hz}$. The values obtained for $\sigma$ " in this frequency range are less than two orders of magnitude lower than the real part of conductivity and orders of magnitude larger than those of all other samples.
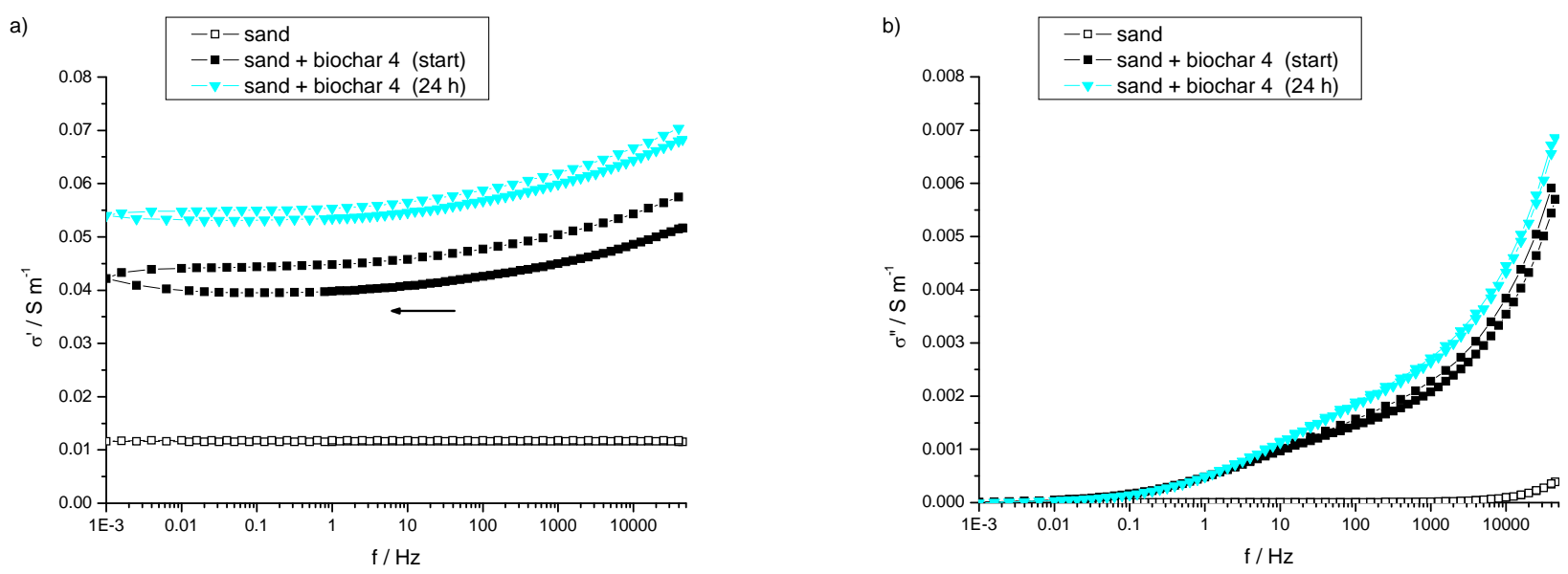

Figure 3: Time dependent plots of $\sigma^{\prime}$ (a) and $\sigma^{\prime \prime}(\mathrm{b})$ for biochar 4

The behavior of the charcoal can be attributed to their chemical properties. The hydrogen content $\mathrm{X}(\mathrm{H})$ of the charcoals expressed as the mass fraction, the $\mathrm{pH}$ and the conductivity $\sigma$ of the liquid after extraction of $1 \mathrm{~g}$ charcoal with $10 \mathrm{ml}$ of demineralized water are shown in Table 1 together with calculated values of the excess conductivity at $1000 \mathrm{~Hz} \sigma_{\text {exc }}$ and the ratio of the conductivity of the samples and the water after extraction $\sigma_{\text {exc }} / \sigma$. The hydrogen content was high for active carbon and biochars 1 and 3 . Note that a mass fraction of $3 \%$ means a composition of about $\mathrm{C}_{2} \mathrm{H}$ suggesting that the materials contained considerable amounts of organic material that was not completely carbonized. Both biochars were pyrolized at lower temperature and with short contact time. The time for biochar 3 was 1 s. Even if it is not known for biochar 1, one can suppose that the time was also short. Biochars 2 and 4 were pyrolized for longer time and showed considerably lower hydrogen content. Biochar 4 which was also pyrolized at much higher temperature and, therefore, showed the lowest hydrogen content. The $\mathrm{pH}$ of the extracts was similar and nearly neutral for biochars 1 and 2. Biochar 3 showed a slightly acidic reaction. The extremes were found for active carbon which yielded a strongly acidic supernatant. In contrast, the $\mathrm{pH}$ found for biochar 4 was alkaline. The large values of the conductivity of the supernatant for active carbon and biochar 4 can be explained in part by these $\mathrm{pH}$ values, because the equivalent conductivity of hydroxyl ions and hydroxide ions is particularly high. The release of acid and base from these products can also explain an increased real part of conductivity $\sigma$ ' for both materials in their mixture with sand. However, the ratio of the excess conductivity of the sand-charcoal mixtures with respect to pure sand is very different for both products. It is much larger for biochar 4, even if the equivalent conductivity of $\mathrm{OH}^{-}$is less than that $\mathrm{H}^{+}$and active carbon is more acidic than biochar 4 is alkaline. Thus, additional properties of biochar 4 must play an important role, as will be explained later. 
Table 1: Chemical properties and conductivity data of active carbon and different biochars

\begin{tabular}{|l|c|c|c|c|c|}
\hline charcoal & $\begin{array}{c}\mathbf{X}(\mathbf{H}) \\
/ \%(\mathbf{w} / \mathbf{w})\end{array}$ & $\begin{array}{c}\mathbf{p H} \\
\text { extraction }\end{array}$ & $\begin{array}{c}\boldsymbol{\sigma} / \mathbf{S ~ m}^{-1} \\
\text { extraction }\end{array}$ & $\begin{array}{c}\boldsymbol{\sigma}_{\text {exc }} / \mathbf{S ~ m}^{-1} \\
\mathbf{S I P}\end{array}$ & $\begin{array}{c}\text { ratio } \\
\boldsymbol{\sigma}_{\text {exc }} / \boldsymbol{\sigma}\end{array}$ \\
\hline $\begin{array}{l}\text { active carbon } \\
\text { 37-149 } \mu \mathrm{m}\end{array}$ & $\begin{array}{c}3.32 \\
\pm 0.00\end{array}$ & 2.3 & 0.3400 & 0.0336 & 0.099 \\
\hline $\begin{array}{l}\text { biochar 1 } \\
\text { from Dynamotive }\end{array}$ & $\begin{array}{c}3.37 \\
\pm 0.02\end{array}$ & 6.2 & 0.0233 & 0.0024 & 0.103 \\
\hline $\begin{array}{l}\text { biochar 2 } \\
\text { barbecue charcoal }\end{array}$ & $\begin{array}{c}2.67 \\
\pm 0.04\end{array}$ & 6.7 & 0.0155 & 0.0035 & 0.226 \\
\hline $\begin{array}{l}\text { biochar 3 } \\
\text { flash pyrolysis }\end{array}$ & $\begin{array}{c}3.60 \\
\pm 0.05\end{array}$ & 4.1 & 0.0118 & 0.0025 & 0.212 \\
\hline $\begin{array}{l}\text { biochar 4 } \\
\text { gasification coke }\end{array}$ & $\begin{array}{c}1.79 \\
\pm 0.12\end{array}$ & 9.8 & 0.1552 & 0.0334 & 0.215 \\
\hline
\end{tabular}

In order to study the influence of grain size on the spectra of $\sigma$ ", measurements on a sieved fraction of biochar 2 with particle size from 1-2 $\mathrm{mm}$ and on active carbon with particle size of 37-149 $\mu \mathrm{m}$ were performed in the closed column. The results are shown in Figure 4. For comparison, the curve of a milled fine powder of biochar 2 in the rectangular sample holder is included in this figure. The response of the sieve fraction is much different from that of the milled sample and shows a distinct maximum at about $3.5 \mathrm{~Hz}$ like the active carbon which had a maximum at $10 \mathrm{~Hz}$. However the particle size $(1-2 \mathrm{~mm})$ of this material is much larger than that of the active carbon $(37-149 \mu \mathrm{m})$ indicating that the size is not the only property which determines the maximum frequency for charcoals. The mechanism of polarization seems to be not only determined by the distribution of ions in the electrical double layer. Since carbonaceous materials are potential electronic conductors, redox processes may be involved (Wong, 1979). The amplitude of $\sigma$ " is much larger than the values found for the milled sample of biochar 2 at this frequency. This may also be also a consequence of the irregular shape of the particles which are considerably elongated (Sillars, 1937).

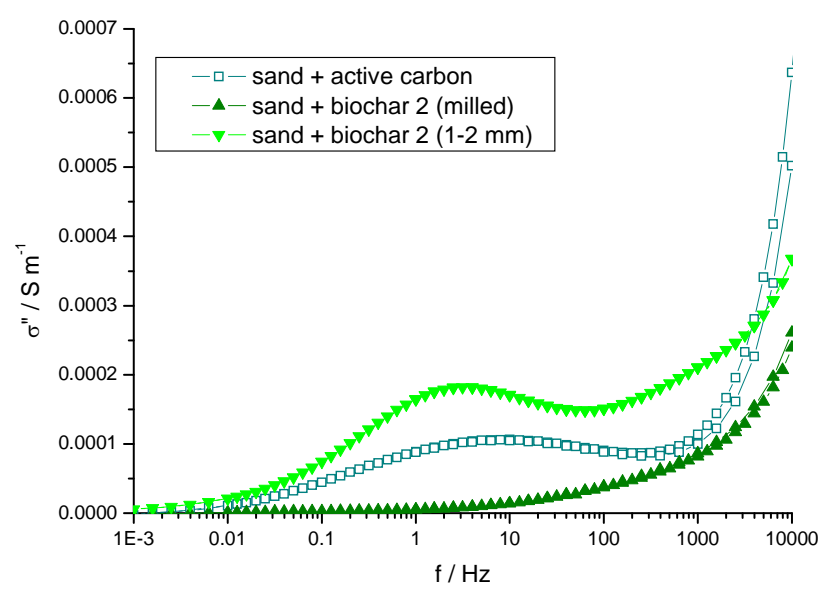

Figure 4: Plot of $\sigma$ " for active carbon, biochar 2 (milled) and biochar 2 (sieve fraction 1-2 mm)

The initial spectra of the imaginary part of conductivity of all charcoals are shown in Figure 5 in a double logarithmic plot. All materials showed an increased imaginary part of conductivity compared with pure sand for frequencies above $1 \mathrm{~Hz}$. At frequencies lower than $0.1 \mathrm{~Hz}$, the values come into the 
limit of the measurement equipment except for the sieve fraction and biochar 4 for which the largest values were obtained. This result shows that biochars influence the electrical properties of sand and that it is in principle possible to find and locate them in soil, at least when comparing the status before and after their application. Thus SIP may be a suitable tool for monitoring processes in soil amended with biochar. The time-dependence of $\sigma$ ' gives information on the ion release from biochar and may be used for determining the influence of biochar on the ion budget in soil.

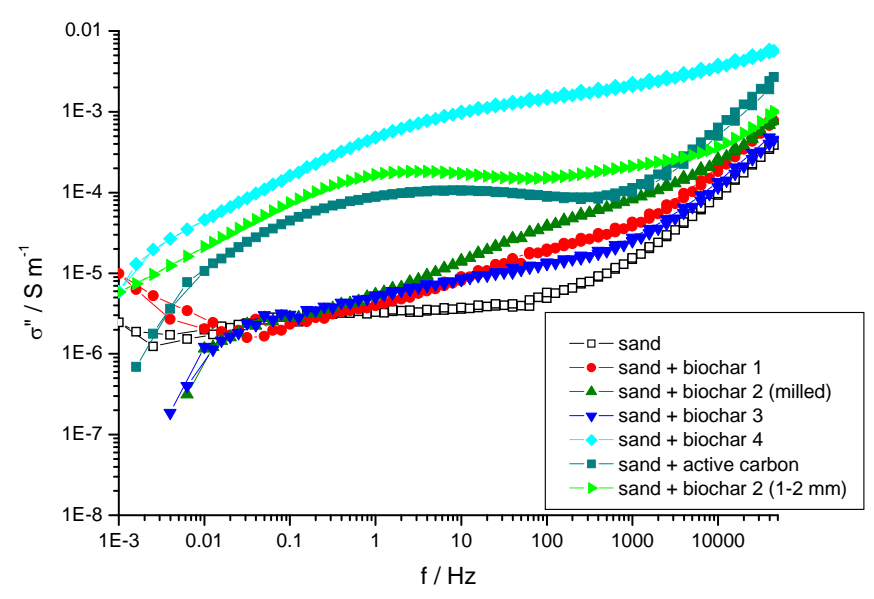

Figure 5: Double logarithmic plot of $\sigma$ " for all biochars

The significant difference in the spectra of different biochars may also be used for characterizing their electronic properties. In Figure 6 the difference $\Delta(\sigma$ ") between the imaginary part of conductivity of sand-charcoal mixtures and pure sand at $2510 \mathrm{~Hz}$ is shown as a function of the hydrogen content. A clear correlation is obtained. The larger the hydrogen content, the smaller is the increase in the imaginary part of the electrical conductivity. Since the hydrogen content is related to the extent of carbonization, which in turn affects electronic conduction, SIP may be useful to monitor changes in the chemical composition of biochar in soil.

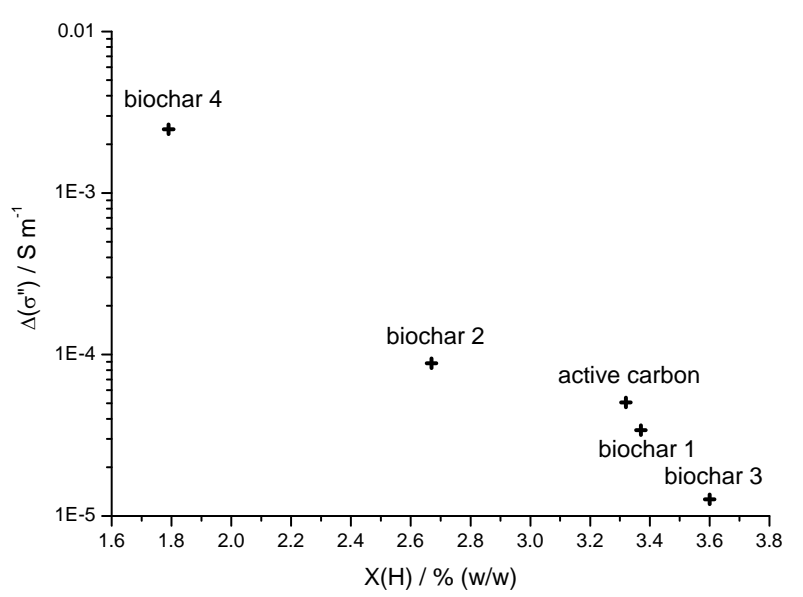

Figure 6: Correlation of $\sigma$ " with hydrogen mass content $\mathrm{X}(\mathrm{H})$ at $2510 \mathrm{~Hz}$ 


\section{Electrical Impedance Tomography}

To test whether electrical impedance tomography (EIT) can be used to locate charcoal in soil, a 2D-experiment was performed. Biochar 4 with the largest response for $\sigma$ ' as well as $\sigma$ " and active carbon with a large response for $\sigma$ ' and a moderate response for $\sigma$ " were used for this experiment. Two structures of sand-charcoal mixtures were built into pure sand. Biochar 4 was placed in the center and active carbon at the margin of the container. The photography of this sample is shown in Figure 7. The $\mathrm{y}$-direction was defined by the location of electrode 1.

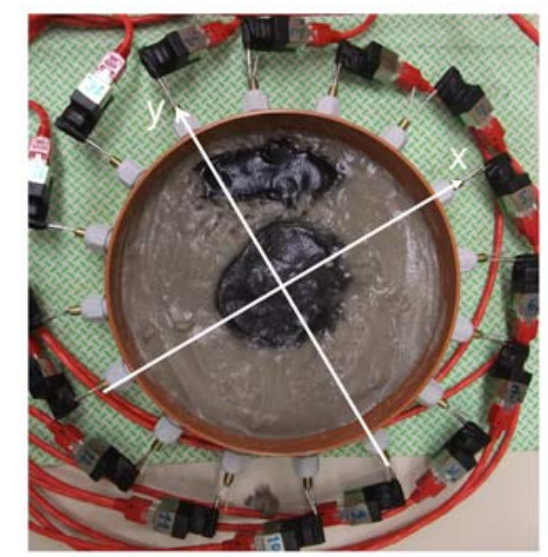

Figure 7: 2D-EIT sample containing sand F36 with structures of active carbon and biochar 4

The images of the distribution of $\sigma$ ' and $\sigma$ " are shown in Figure 8. The real part of conductivity at $100 \mathrm{~Hz}$ can be well detected for both materials, but the position of active carbon is not exact. It is too narrow to the margin. This mismatch has already been found in a cylindrical container and was attributed to the fact that the number of voxels increases with increasing distance from the center of a cylindrical column and errors of the measurement data can be better compensated when the structure shifts to the margin (Haegel et al., 2011).

a)

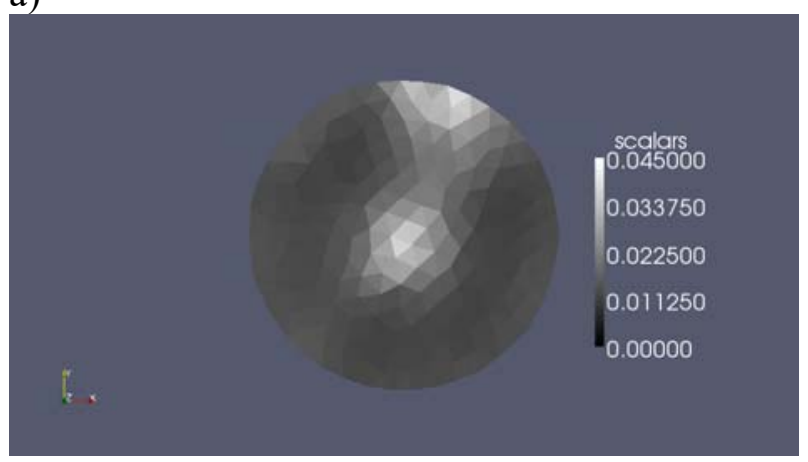

b)

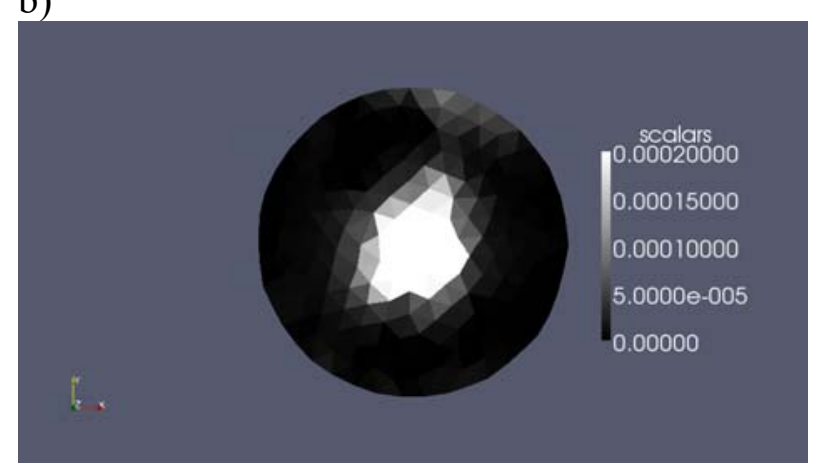

Figure 8: Tomographic images of $\sigma^{\prime}$ (a) and $\sigma^{\prime \prime}(b)$ for the 2D-EIT sample

The response of the phase angle at $100 \mathrm{~Hz}$ is also large for biochar 4, but even active carbon with a lower contrast can still be detected. The magnitudes of $\sigma$ ' and $\sigma$ " in the images correspond well with the data found with SIP (Figures 1 and 3). This result shows that EIT is potentially suitable for localizing biochar in soil. Since EIT can be used also for larger scales, it shows promise for the non- 
invasive characterization and monitoring of biochars in the field. Preliminary results on samples which were not completely water saturated did also show changes of SIP, but this subject is still under investigation.

\section{Conclusions}

The spectral electrical response of biochar in sand depends on its chemical composition which is a result of the type of feed material and the parameters of the pyrolysis process. The imaginary part of complex conductivity is also influenced by the particle size. Therefore SIP can be used as an additional method for the characterization of biochar. The real part of complex conductivity is influenced by the release of ions from biochar. Thus SIP and EIT are potentially suitable for monitoring the long-term ion budgets in soils cultivated with biochar. Investigating the influence of biochar on the hydraulic properties of soil with SIP and EIT would be a next reasonable step.

\section{References}

Börner, F. D., Schopper, J. R., Weller, A., 1996, Evaluation of transport and storage properties in the soil and groundwater zone from induced polarization measurements, Geophysical Prospecting, 44(4), 583-601. DOI: 10.1111/j.1365-2478.1996.tb00167.x

Breede, K., Kemna, A., Esser, O., Zimmermann, E., Vereecken, H., Huisman, J. A., 2011, Joint Measurement Setup for Determining Spectral Induced Polarization and Soil Hydraulic Properties, Vadose Zone Journal, 10(2), 716-726. DOI: 10.2136/vzj2010.0110

Brewer, C. E., Schmidt-Rohr, K., Satrio, J. A., Brown, R. C., 2009, Environmental Progress \& Sustainable Energy, 28(3), 386-396. DOI: 10.1002/ep.10378

Brockhoff, S. R., Christians, N. E., Killorn, R. J., Horton, R., Davis, D. D., 2010, Physical and MineralNutrition Properties of Sand-Based Turfgrass Root Zones Amended with Biochar, Agronomy Journal, 102(6), 1627-1631. DOI: 10.2134/agronj2010.0188

Cassiani, G., Kemna, A., Villa, A., Zimmermann, E., 2009, Spectral induced polarization for the characterization of free-phase hydrocarbon contamination of sediments with low clay content, Near Surface Geophysics, 7(5-6), 547-562

deGroot-Hedlin, C., Constable, S., 1990, Occam's inversion to generate smooth, two-dimensional models from magnetotelluric data, Geophysics, 55(12), 1613-1624.

Dumroese, R. K., Heiskanen, J., Englund, K., Tervahauta, A., 2011, Pelleted biochar: Chemical and physical properties show potential use as a substrate in container nurseries, Biomass \& Bioenergy, 35(5), 2018-2027. DOI: 10.1016/j.biombioe.2011.01.053

Flores Orozco, A., Williams, K. H., Long, P. E., Hubbard, S. S., Kemna, A., 2011, Using complex resistivity imaging to infer biogeochemical processes associated with bioremediation of an uranium-contaminated aquifer, Journal of Geophysical Research, Journal of Geophysical Research, 116, G03001, 17 pp. DOI: 10.1029/2010JG001591

Haegel, F.-H., Zimmermann, E., Esser, O., Huisman, J. A., Glaas, W., Berwix J., Vereecken, H., 2011, Determination of the distribution of air and water in porous media by electrical impedance tomography and magneto-electrical imaging, Nuclear Engineering and design, 241(6), 19591969. DOI: 10.1016/j.nucengdes.2010.09.011

Hördt, A., Blaschek, R., Kemna, A., Zisser, N., 2007, Hydraulic conductivity estimation from induced polarisation data at the field scale - the Krauthausen case history, Journal of Applied Geophysics, 62(1), 33-46. DOI: 10.1016/j.jappgeo.2006.08.001 
Hördt, A., Druiventak, A., Blaschek, R., Binot, F., Kemna, A., Kreye, P., Zisser, N., 2009, Case histories of hydraulic conductivity estimation with induced polarization at the field scale, Near Surface Geophysics, 7(5-6), 529-545.

Jha, P., Biswas A. K., Lakaria B. L., Rao, A. S., 2010, Biochar in agriculture - prospects and related implications, Current Science, 99(9), 1218-1225.

Koch, K., Kemna, A., Irving J., Holliger K., 2011, Impact of changes in grain size and pore space on the hydraulic conductivity and spectral induced polarization response of sand, Hydrology and Earth System Sciences, 15(6), 1785-1794. DOI: 10.5194/hess-15-1785-2011

Kookana, R. S., Sarmah, A. K., Van Zwieten, L., Krull, E., Singh, B., 2011, Biochar Application to Soil: Agronomic and Environmental Benefits and Unintended Consequences, Sparks, D. L., Ed., Advances in Agronomy, 112, 103-143. DOI: 10.1016/B978-0-12-385538-1.00003-2

Kwon, Y. W., Bang, H., 1997, The Finite Element Method using MATLAB, CRC Press, Boca Raton, FL.

Laird, D. A., Fleming, P., Davis D. D., Horton, R. Wang, B. Q., Karlen, D. L., 2010, Impact of biochar amendments on the quality of a typical Midwestern agricultural soil, Geoderma, 158(3-4), 443449. DOI: $10.1016 /$ j.geoderma.2010.05.013

Lehmann, J., 2007, Bio-energy in the black, Frontiers in Ecology and the Environment, 5(7), 381-387. DOI: 10.1890/1540-9295(2007)5[381:BITB]2.0.CO,2

Lehmann, J.; Rillig, M. C.; Thies, J., Masiello, C. A., Hockaday, W. C., Crowley D., 2011, Biochar effects on soil biota - A review, Soil Biology \& Biochemistry, 43(9), 1812-1836. DOI: 10.1016/j.soilbio.2011.04.022

Leroy, P., Revil, A., Kemna, A., Cosenza, P., Ghorbani, A., 2008, Complex conductivity of watersaturated packs of glass beads, Journal of Colloid and Interface Science, 321(1), 103-117. DOI: 10.1016/j.jcis.2007.12.031

Leroy, P., Revil, A., 2009, A mechanistic model for the spectral induced polarization of clay materials, Journal of Geophysical Research, 114, B10202. DOI: 10.1029/2008JB006114

Revil A., Skold M., 2011, Salinity dependence of spectral induced polarization in sands and sandstones, Geophysical Journal International, 187(2), 813-824. DOI: 10.1111/j.1365-246X.2011.05181.x

Schmutz M., Revil A., Vaudelet P., Batzle, M., Viñao, P. F., Werkema, D. D., 2010, Influence of oil saturation upon spectral induced polarization of oil-bearing sand, Geophysical Journal International, 183(1), 211-224. DOI: 10.1111/j.1365-246X.2010.04751.x

Sharma P., Bhatti T. S., 2010, A review on electrochemical double-layer capacitors, Energy Conversion and Manangement, 51(12), 2901-2912. DOI: 10.1016/j.enconman.2010.06.031

Sillars R. W., 1937, The properties of a dielectric containing semiconducting particles of various shapes, Journal of the Institution of Electrical Engineers, 80(484), 378-394

Skold, M., Revil, A., Vaudelet, P., 2011, The pH dependence of spectral induced polarization of silica sands: Experiment and modelling, Geophysical Research Letters, 38, L12304, 6 pp. DOI: 10.1029/2011GL047748

Slater, L., Ntarlagiannis, D., Personna, Y. R., Hubbard, S., 2007, Pore-scale spectral induced polarization signatures associated with $\mathrm{FeS}$ biomineral transformations, Geophysical Research Letters, 34(21), L21404, 5pp. DOI: 10.1029/2007GL031840

Slater, L., 2007, Near surface electrical characterization of hydraulic conductivity: From petrophysical properties to aquifer geometries - A review, Surveys in Geophysics, 28(2-3), 169-197. DOI: 10.1007/s10712-007-9022-y

Sohi, S. P., Krull, E., Lopez-Capel, E., Bol, R., 2010, A Review of Biochar and Its Use and Function in Soil, Sparks, D. L., Ed., Advances in Agronomy, 105, 47-82, . DOI: 10.1016/S00652113(10)05002-9 
Uzoma, K. C., Inoue, M., Andry, H., Fujimaki, H., Zahoor, A., Nishihara, E., 2011, Effect of cow manure biochar on maize productivity under sandy soil condition, Soil Use and management, 27(2), 205-212. DOI: 10.1111/j.1475-2743.2011.00340.x

Vanhala, H., Peltoniemi, M., 1992, Spectral IP studies of Finnish ore prospects, Geophysics, 57(12), 1545-1555. DOI: $10.1190 / 1.1443222$

Vaudelet, P., Revil, A., Schmutz, M., Franceschi, M., Bégassat, P., 2011 a , Induced polarization signatures of cations exhibiting differential sorption behaviors in saturated sands, Water Resources Research, 47, W02526, 21 pp. DOI: 10.1029/2010WR009310

Vaudelet, P., Revil, A., Schmutz, M., Franceschi, M., Bégassat, P., 2011 ${ }^{\mathrm{b}}$, Changes in induced polarization associated with the sorption of sodium, lead, and zinc on silica sands, Journal of Colloid and Interface Science, 360(2), 739-752. DOI: 10.1016/j.jcis.2011.04.077

Weller, A., Börner, F. D., 1996, Measurements of spectral induced polarization for environmental purposes, Environmental Geology, 27(4), 329-334.

Weller, A., Slater, L., Nordsiek, S., Ntarlagiannis, D., 2010, On the estimation of specific surface per unit pore volume from induced polarization: A robust empirical relation fits multiple data sets, Geophysics, 75(4), WA105-WA112. DOI: 10.1190/1.3471577

Williams, K. H., Kemna, A., Wilkins, M. J., et al., 2009, Geophysical Monitoring of Coupled Microbial and Geochemical Processes During Stimulated Subsurface Bioremediation, Environmental Science and Technology, 43(17), 6717-6723. DOI: 10.1021/es900855j

Wong, J., 1979, Electrochemical Model of the induced-polarization phenomenon in disseminated sulfide ores, Geophysics, 44(7), 1245-1265. DOI: 10.1190/1.1441005

Wong, J., Strangway, D. W., 1981, Induced polarization in disseminated sulfide ores containing elongated mineralization, Geophysics, 46(9), 1258-1268. DOI: 10.1190/1.1441264

Zimmermann, E., Kemna, A., Berwix J., Glaas, W., Münch, H. M., Huisman, J. A., 2008a, A highaccuracy impedance spectrometer for measuring sediments with low polarizability, Measurement Science \& Technology, Measurement Science \& Technology, 19(9), 094010, 9 pp. DOI: 10.1088/0957-0233/19/9/094010

Zimmermann, E., Kemna, A., Berwix J., Glaas, W., Vereecken, H., 2008 ${ }^{\text {b }}$, EIT measurement system with high phase accuracy for the imaging of spectral induced polarization properties of soils and sediments, , Measurement Science \& Technology, 19(10), 105603, 9pp. DOI: 10.1088/09570233/19/10/105603

\section{Acknowledgements}

The authors thank Nils Borchard from University of Bonn for providing us with biochars 3 and 4. We are also grateful to Joseph Pignatello and Jason White (CAES, CT, USA) for providing biochar 1. Furthermore, we thank Andreas Linden for performing some of the measurements. We also thankfully acknowledge the chemical analysis by the Central Division of analytical Chemistry of Forschungszentrum Jülich. 